\title{
Education corner
}

\section{Ovarian follicular atresia: a model for apoptosis}

\author{
Massimo De Felici
}

Department of Public Health and Cell Biology, University of Rome 'Tor Vergata', Rome, Italy

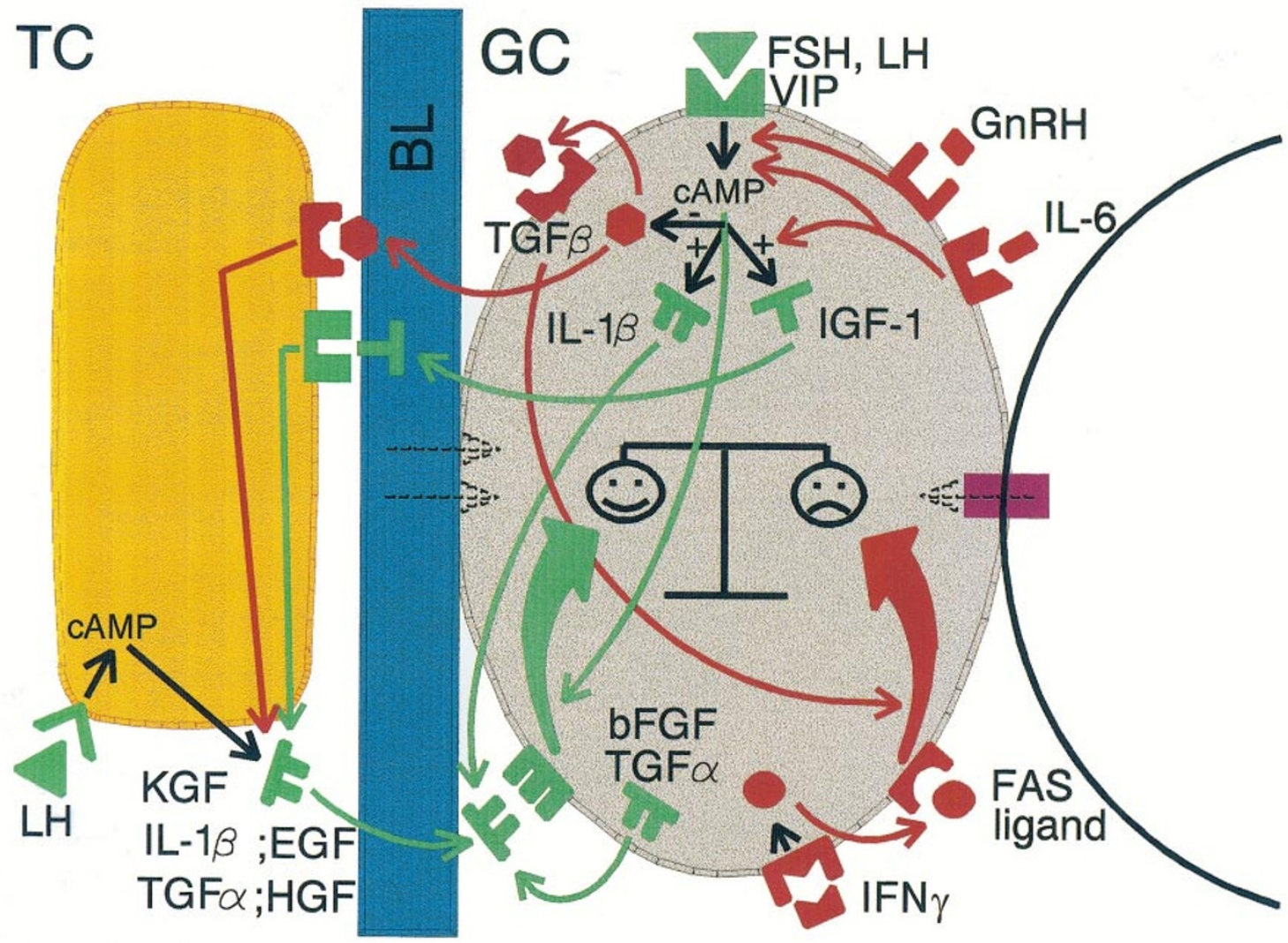

(C) Cell Death Differ. by M De Felici

This figure shows complex intraovarian hormonal and growth factor interactive networks that can favour survival (green symbols) or induce apoptosis/atresia (red symbols) of granulosa cells. Based mainly on studies of cultured rat and mouse follicles, current data suggest that cAMP increase in granulosa cells (GC), induced from the actions of endocrine (FSH, LH) and neural-derived factors (vasoactive intestinal peptide (VIP), results in increased levels of insulin-like transforming growth factor (IGF-1) and interleukin-1 $\beta$ (IL-1 $\beta$ ) and decreased levels of transforming growth factors- $\beta$ (TGF- $\beta$ ). Whereas IGF-1 serves as a paracrine signal for theca cells (TC) to increase the production of other growth factors (keratinocyte growth factor, KGF; hepatocyte growth factor, HGF; epidermal growth factor, EGF; transforming growth factor- $\alpha$, TGF- $\alpha$; interleukin- $1 \beta$, IL- $1 \beta$ ), IL- $1 \beta$ may act as an autocrine factor. cAMP might also exert its survival action through still non-identified growth factor-independent pathways. Basic fibroblast growth factor (bFGF) and TGF- $\alpha$ produced by granulosa cells may suppress apoptosis through autocrine mechanisms. The actions of these 'survival' factors are in turn modulated by the opposing actions of apoptotic factors such as GnRH, IL-6, TGF- $\beta$, tumor necrosis factor- $\alpha$ $(T N F \alpha)$. Finally, recent studies indicate that FAS ligand is produced by granulosa cells under the action of interferon- $\gamma$ (IFN- $\gamma$ ) and may be an important effector of apoptosis in such cells. Granulosa cell interactions through gap junctions and granulosa cell-basal lamina (BM) interactions are represented as hypothetical (dashed arrows) as they might play a key role in determining the fate of granulosa cells. For clarity's sake, the actions of androgens and estrogens/progesterone are not shown, although they can be involved as autocrine or paracrine mediators in promoting and preventing follicular atresia, respectively. A listing of potential 'downstream effectors' that may mediate the final pro- and anti-apoptotic effects of gonadotropins and growth factors in granulosa cells can be found in the Recommended Readings. 


\section{Recommended Readings}

Hsueh AJW, Billig H and Tsafriri A (1994) Ovarian follicle atresia: a hormonally controlled apoptotic process. Endocrine Rew. 15: 707-724

Tilly JL (1993) Ovarian follicular atresia: a model to study the mechanisms of physiological cell death. Endocrine J. 1:67-72

Tilly JL (1996) Apoptosis and ovarian function. Rev. Reprod. 1: 162-172
Tilly JL (1996) The molecular basis of ovarian cell death during germ cell attrition, follicular atresia and luteolysis. Frontiers in Bioscience 1: 1-11

Tilly JL and Tilly KI (1997) The genes of cell death and cellular susceptibility to apoptosis in the ovary: a hypothesis. Cell Death Diff. 4: 180-187 